\title{
HIGH QUALITY ZnSe AND Zn(Se,S) PRODUCED BY LOW TEMPERATURE PHYSICAL VAPOUR TRANSPORT
}

\author{
A. Mycielski, A. Szadkowski, L. KowalczyK AND A. ZaręBA \\ Institute of Physics, Polish Academy of Sciences \\ Al. Lotników 32/46, 02-668 Warsaw, Poland
}

High quality, large (25 $\mathrm{mm}$ in diameter) crystals of $\mathrm{ZnSe}$ and $\mathrm{Zn}(\mathrm{Se}, \mathrm{S})$ were grown by low-temperature physical vapour transport method and characterized by various techniques, i.e. energy dispersive $\mathrm{X}$-ray fluorescence spectrometry, double-crystal X-ray diffraction rocking curve FWHM, reflectivity measurements in the region of free exciton, electrical measurements and photoluminescence measurements for both low and high excitation densities. The measurement of the photoluminescence related to the neutral-donor-bound exciton revealed superlinear $\log$ (photoluminescence intensity) versus $\log$ (excitation intensity) dependence, which indicates stimulated emission phenomena.

PACS numbers: 81.05.Dz, 78.55.Et, 78.45.th

The early development of II-VI light emitters was achieved by growing MBE films on $\mathrm{ZnSe}$ substrates prepared from Bridgman grown ingots. This material is highly strained with defect densities above $10^{8} \mathrm{~cm}^{-2}$. Now, most researchers opt for grow $\mathrm{ZnSe-based} \mathrm{light-emitting} \mathrm{structures} \mathrm{on} \mathrm{the} \mathrm{commercially} \mathrm{available} \mathrm{GaAs.}$ However, because of the difference in the thermal expansion coefficients between the GaAs substrate and the $\mathrm{ZnSe}$ or $\mathrm{Zn}(\mathrm{Se}, \mathrm{S})$ epilayers, a tensile strain exists at the hetero-interface and provokes stacking faults and dislocations. Moreover, the interdiffusion effects at the II-VI/III--V hetero-interface can cause imperfect nucleation.

To overcome these problems we have decided to develop the technology of high quality $\mathrm{ZnSe}_{1-x} \mathrm{~S}_{x}$ substrates with $x$ values: $0.04,0.07$ and 0.10 (from now on, " $x$ " will stand for the sulphur content).

Substrate wafers $(15 \mathrm{~mm} \times 15 \mathrm{~mm})$ are cut from oriented, $25 \mathrm{~mm}$ in diameter and about $25 \mathrm{~mm}$ long single crystal $\mathrm{Zn}(\mathrm{Se}, \mathrm{S})$ ingots, which have been grown at about $1150^{\circ} \mathrm{C}$, instead of $1550 \div 1600^{\circ} \mathrm{C}$ used for the Bridgman method. The crystal ingots are twin-free and contain no low-angle grain boundaries. To grow the crystals we used the technique of physical vapour transport (PVT), similar to that described in Ref. [1]. 
The $\mathrm{ZnSe}$ and $\mathrm{ZnS}$ powders were synthesized from high-purity elements: $\mathrm{Zn}(6 \mathrm{~N}), \mathrm{Se}(5 \mathrm{~N} 6)$ and $\mathrm{S}(5 \mathrm{~N} 6)$. Purification of $\mathrm{Zn}, \mathrm{Se}$, and $\mathrm{S}$ was carried out in our laboratory and verified by the spark source mass spectrometry. The synthesized powders were used as starting materials for the growth of both $\mathrm{ZnSe}$ and $\mathrm{Zn}(\mathrm{Se}, \mathrm{S})$ crystals. The ampoules, having inner diameter $25 \mathrm{~mm}$ and conical tips, were placed in a furnace in the horizontal position in such a way that the end with the source material was at $1150^{\circ} \mathrm{C}$. The crystal grew from the other end. After formation of a seed in the tip, the ampoule travelled with the rate $3 \mathrm{~mm} /$ day. $\mathrm{X}$-ray analyses of the obtained crystals confirmed pure zinc-blende structure without any hexagonal inclusions. The composition and homogeneity of the obtained ternary crystals were determined by energy dispersive X-ray fluorescence (EDXRF) spectrometry. For example, for $\mathrm{Zn}(\mathrm{Se}, \mathrm{S})$ with $x=0.10$ we found $x=0.10 \pm 0.005$ over the distance of $2 \mathrm{~cm}$ along an ingot. The results of the double-crystal X-ray diffraction rocking curve (FWHM) measurements range from $25^{\prime \prime}$ to $35^{\prime \prime}$. The typical etch pit densities (NaOH etchant) on the (110) cleaved surface range from $10^{4} \mathrm{~cm}^{-2}$ to $10^{5} \mathrm{~cm}^{-2}$. Reflectivity measurements on the cleaved surface have been performed at $1.8 \mathrm{~K}$ in the spectral region $2 \div 3 \mathrm{eV}$. The only structures which were found for $\mathrm{ZnSe}$ and $\mathrm{Zn}(\mathrm{Se}, \mathrm{S})$ belong to free exciton (FE), i.e. they are about $20 \mathrm{meV}$ below the value of the energy gap. An example of such a structure for the crystal with $x=0.07$ is shown in Fig. 1.

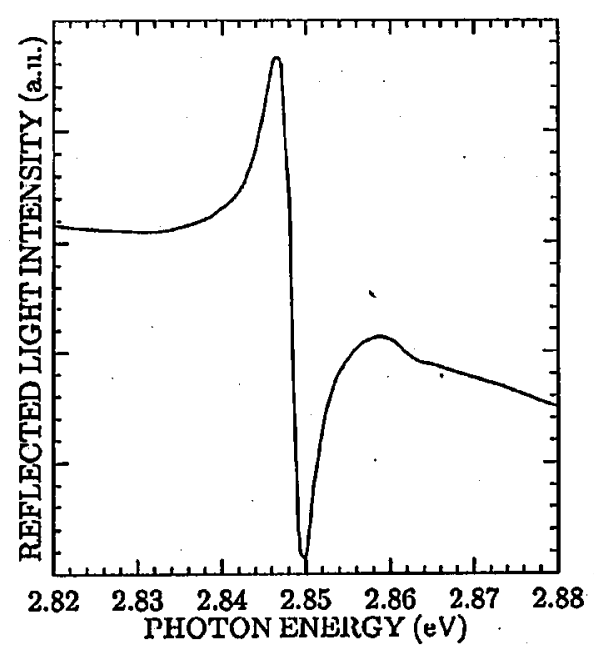

Fig. 1. Reflection spectrum in the exciton range (at $1.8 \mathrm{~K}$ ) of $\mathrm{Zn}(\mathrm{Se}, \mathrm{S}), x=0.07$.

For $\mathrm{ZnSe}$ the energy of the free exciton (FEE) is $2.8025 \mathrm{eV}$. For $\mathrm{Zn}(\mathrm{Se}, \mathrm{S})$ this energy depends on the composition, and for the sulphur content not exceeding $x=0.15$ follows the expression:

$\mathrm{FEE}=2.802 \mathrm{eV}+x \cdot 0.65 \mathrm{eV}$.

The comparison of the FE-related structures for the crystals with various compositions has shown that the higher $\mathrm{S}$ content - the broader the structure. For ex- 
ample, the distance between maximum and minimum of the reflectivity is $3.2 \mathrm{meV}$ and $6.3 \mathrm{meV}$ for $\mathrm{Zn}(\mathrm{Se}, \mathrm{S})$ crystals with $x$-values 0.07 and 0.12 , respectively. Since EDXRF analyses of ternary crystals do not indicate any segregation of sulphur with respect to selenium, we ascribe the broadening of the $\mathrm{FE}$ structure to a micro-scale $(30 \div 50 \AA)$ chemical disorder that may be expected in the ternary compounds. Photoluminescence (PL) measurements were carried out at $1.8 \mathrm{~K}$. The luminescence of the crystals was excited by a $\mathrm{He}-\mathrm{Cd}$ laser with $325 \mathrm{~nm}$ wavelength $(3.8 \mathrm{eV})$. The PL spectrum (Fig. 2) of a $\mathrm{Zn}(\mathrm{Se}, \mathrm{S})$ crystal with $x=0.12$ is dominated by a strong neutral-donor-bound exciton $\left(D^{0} \mathrm{X}\right)$ line. This crystal was grown without any excess of Se and therefore (because of the small number of $\mathrm{Zn}$ vacancies) the manifestation of the donor-related phenomena was expected in the samples. For the same reason the donor-acceptor-pair (DAP) luminescence is not observed for this crystal.

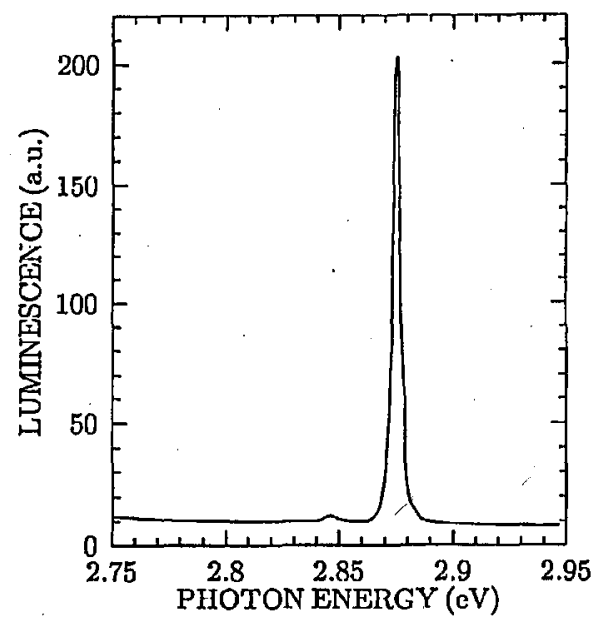

Fig. 2. Photoluminescence spectrum in the exciton range (at $1.8 \mathrm{~K}$ ) of $\mathrm{Zn}(\mathrm{Se}, \mathrm{S}$ ) crystal, $x=0.12$, grown without any excess of selenium. The large peak at $2.875 \mathrm{eV}$ represents the neutral-donor-bound exciton $\left(D^{0} \mathrm{X}\right)$ luminescence. The dependence of this luminescence on the excitation intensity (for high excitations) is shown in Fig. 3 (sample S1).

The spectra of the $\mathrm{Zn}(\mathrm{Se}, \mathrm{S})$ crystals which have been prepared with a very small excess of Se contained strong lines related to both donor-bound excitons and acceptor-bound excitons. Also in those crystals the DAP luminescence was absent.

On the other hand - the PL spectrum of a $\mathrm{ZnSe}$ crystal which was prepared with a little larger excess of Se was dominated by the strong DAP luminescence. The main feature of the excitonic part of this spectrum was the line at $2.783 \mathrm{eV}$ (i.e. about $10 \mathrm{meV}$ below the lines related to the excitons bound to typical shallow acceptors). This line has been ascribed by Pohl et al. [2] to an exciton bound to a complex acceptor. The complex consists of the zinc vacancy and an impurity donor (e.g. interstitial Li). Since our crystal was prepared with the excess of Se, the presence of zinc vacancies favoured the formation of those complexes. 
An addition of $\mathrm{ZnCl}_{2}$ to the source material was used as a method of $\mathrm{Cl}$-doping. The PL spectra of the Cl-doped $\mathrm{Zn}(\mathrm{Se}, \mathrm{S})$ crystals were dominated by a typical, very broad feature near $2 \mathrm{eV}$. While the crystals grown without $\mathrm{Cl}$ were semi-insulating, the chlorine doped crystals were conducting and the room-temperature measurements of the thermoelectric power and Hall effect have confirmed $n$-type conductivity. The concentration of electrons in a sample annealed in $\mathrm{Zn}$ vapour was $5 \times 10^{17} \mathrm{~cm}^{-3}$ at room temperature.

The studies of the photoluminescence in the conditions of high excitation intensity were carried out using nanosecond pulses from a frequency-tripled Nd:YAG laser and from the dye laser pumped by the YAG laser. The intensity $L$ of the photoluminescence was measured as a function of the excitation intensity $I$ and particularly interesting was the behaviour of the $\mathrm{D}^{0} \mathrm{X}$ luminescence. Results of the measurements are presented in Fig. 3. The sample $\mathrm{S} 1$ is from the $\mathrm{Zn}(\mathrm{Se}, \mathrm{S})$ crystal grown without any excess of Se. Samples S2 and S3 are from the crystals grown with an excess of Se. Superlinear $\log L-\log I$ relation for the $\mathrm{D}^{0} \mathrm{X}$ luminescence is clearly seen, especially for S1. On the contrary, the DAP luminescence presents a simple linear $L-I$ relation even for very high excitation intensities.

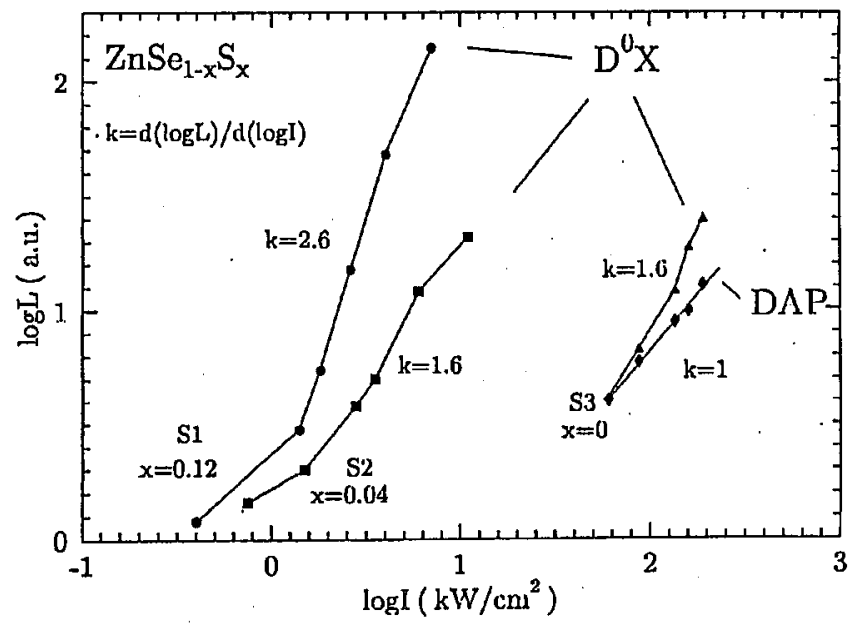

Fig. 3. Photoluminescence intensity $L$ versus excitation intensity $I$ in the region of high excitation densities for the $\mathrm{Zn}(\mathrm{Se}, \mathrm{S})$ crystals (samples $\mathrm{S} 1$ and $\mathrm{S} 2$ ) and for the $\mathrm{ZnSe}$ crystal (sample S3). Samples S2 and S3 are from the crystals grown with an excess of Se. For each curve the maximum value of $k$ is indicated.

It was found by various authors, e.g. [3], that the near-band-edge photoluminescence in II-VI semiconductors can be described by the power dependence on the excitation intensity: $L \propto I^{k}$, where $k$ is between 1 and 2 . The results presented in Fig. 3 show that for high excitation intensity the very value of $k$ depends on $I$. Maximum value of $k(2.6)$ occurred for the $\mathrm{D}^{0} \mathrm{X}$ luminescence of the sample S1, for which $D^{0} \mathrm{X}$ luminescence is the only significant feature in the near-band-edge photoluminescence (see Fig. 2). The superlinear $\log L-\log I$ relation (i.e. increas- 
ing $k$ ) and the high value of $k(2.6)$ are characteristic of the stimulated emission phenomena. We believe that those $\mathrm{Zn}(\mathrm{Se}, \mathrm{S})$ crystals, in which the radiative annihilation of $\mathrm{D}^{0} \mathrm{X}$ represents a very effective recombination channel, offer a possibility to obtain stimulated emission connected with this transition.

Concluding - we have shown that the high quality $\mathrm{Zn}(\mathrm{Se}, \mathrm{S})$ crystals with prospective applications in optoelectronic devices can be grown by low temperature PVT, using stoichiometric charge or small excess of Se.

This work was supported in part by the Committee for Scientific Research under grant No. 1001/T11/95/08.

\section{References}

[1] W.W. Piper, S.J. Polich, J. Appl. Phys. 32, 1278 (1961).

[2] U.W. Pohl, G.H. Kudlek, A. Klimakow, B. Hoffman, J. Cryst. Growth 138, 385 (1994).

[3] T. Schmidt, G. Daniel, K. Lischka, J. Cryst. Growth 117, 748 (1992). 